$\begin{array}{llllllll}R & E & S & E & N & H & A & S\end{array}$

Das páginas deste livro emerge um feixe de experimento de idéias, dado pela elegância na escrita, o cuidado com a textura e o significado das palavras. Qualidades estas transmitidas pela "boa tradução" do livro, que nos oferece a difícil tarefa de conciliar e manter as diferenças entre línguas diferentes e criar sobre o intraduzível. Ao terminar a leitura, temos um sentido restituído: o de que o mundo ainda apresenta novidade. Massey traz um pouco de "ar puro" para a Geografia. "Lugares, em vez de serem localizações de coerência, tornam-se os focos do encontro e do não-encontro do previamente não-relacionado e, assim, essenciais para a geração do novo" (p. 111). A amplitude de seus questionamentos nos permite multiplicar os olhos, gesto esse especialmente urgente para pensar as questôes contemporâneas. Há em suas reflexões uma serenidade epistemológica para questôes tão complicadas e densas, como o acesso e controle desigual do poder. Posição essa que somente a maturidade de uma rica trajetória intelectual pode oferecer.

Em síntese, para que a teoria de Massey seja compreendida, é fundamental termos em mente que sua crítica é direcionada a todas as abordagens positivistas e essencialistas que cultivam uma idéia de lugar circunscrito e fadado a uma única identidade. Pensar desta maneira o lugar é empobrecer o cotidiano, as experiências contemporâneas, o mundo e o devir. Com todas as implicações políticas, como legado de uma representação de mundo colonialista, não é mais possível pensarmos o espaço como superfície plana. Ancorar-se nesta interpretação é silenciar as muitas outras vozes e muitos outros atores que formam o espaço. Nesta direção, as Ciências Humanas e os atores do planejamento, nas mais diversas escalas de ação, podem e devem assumir o compromisso de elaborar uma reflexão e ação política para construção de um espaço heterogêneo, múltiplo e plural, pois essa é a única condição humana da qual somos herdeiros.

\section{SÃo PAULO, CIDADE GLOBAL: FUNDAMENTOS FINANCEIROS DE UMA MIRAGEM}

Mariana Fix

São Paulo: Boitempo, 2007

Daniela Abritta Cota

Doutoranda do Programa de Pós-Graduação em Geografia da UFMG

A transição do regime de acumulação fordista para o regime de acumulação flexível levou, em muitos casos, à adoção pelos países centrais de formas mais flexíveis de organização espacial, seja do ponto de vista das normas de ordenamento territorial, seja nas formas de relacionamento entre o poder público e o setor privado. Por outro lado, o processo de globalização e de flexibilização da produção, bem como a quebra das barreiras espaciais (Harvey, 1995) como consequiência da contínua revolução nos meios de transporte e de comunicação, reforçaram a política do local e a importância dos lugares, que passaram a competir pela atração de investimentos e fluxos de consumo. Nesse contexto, produtividade, competitividade e subordinação dos fins à lógica do mercado são elementos que dominam a "nova" forma de se pensar o urbano, constituindo o que Harvey chamou de empresariamento da gestão urbana (Harvey, 1996). Tais elementos passam, assim, a ser incluídos na discussão de políticas urbanas locais mais recentes, sendo adotados especialmente por aquelas cidades com "vocação global". Nesse contexto de transformação da "cidade-empresa", instrumentos de planejamento mais flexíveis - contrapondo-se aos tradicionais, tanto do ponto de vista da regulação do uso e da ocupação do solo urbano quanto da governança urbana - são colocados em pauta tanto nos países centrais quanto nos periféricos, a exemplo da parceria públicoprivada, que se apresenta como possível mecanismo de captação de recursos e de gestão pública eficaz, considerando o seu papel na promoção da inserção competitiva de cidades nos fluxos econômicos globais.

Mariana Fix, em sua última obra (Fix, 2007), dá abertura para diferentes reflexões, nos instigando, inclusive, a refletir sobre este tema - a parceria públicoprivada - quando investiga as conexóes existentes en- 
tre capital imobiliário e capital financeiro na cidade de São Paulo, metrópole periférica, em um contexto de mundialização da economia. Destaca-se na investigação realizada pela autora especialmente a riqueza do trabalho de campo e o expressivo número de entrevistas qualitativas realizadas ao longo da pesquisa - 56 entrevistas envolvendo 61 pessoas de 46 entidades diferentes -, capazes de subsidiar o entendimento e as reflexões acerca do circuito de circulação do capital no meio ambiente construído. Mérito também deve ser conferido à clareza com que Fix apresenta os novos mecanismos financeiros que podem, em tese, aproximar o mercado imobiliário do modo de funcionamento do mercado de capitais, a exemplo dos fundos de investimentos utilizados no caso brasileiro.

A discussão realizada pela autora tem como objeto de estudo uma parte da cidade de São Paulo que se projeta como uma nova centralidade - Faria LimaBerrini, também alvo de análise da autora em suas obras anteriores (Fix, 2001, 2003) - ao ser submetida às estratégias de planejamento e gestão capazes de produzir a "face globalizada" da metrópole. Nesse livro, a autora procura identificar as formas assumidas na produção imobiliária e no consumo do espaço urbano de São Paulo, investigando como a financeirização e a mundialização do capital produzem paisagens como esta, objeto de seu estudo: torres de escritórios, shopping centers, prédios de uso misto, dentre outros exemplares existentes nas paisagens dos centros de negócios dos países centrais.

Por trás dessa aparente paisagem globalizada, Fix identifica as estratégias colocadas em prática para viabilizar a cidade global, mostrando como em São Paulo o elo entre mercado imobiliário e capital financeiro se mostra truncado e imperfeito, evidenciando as características específicas que essa aliança assume na realidade brasileira.

Primeiramente, a análise busca mostrar que a produção do ambiente construído, resultado desse elo em São Paulo, não conta com um crédito efetivo, como é o caso das hipotecas nos Estados Unidos. Na falta de crédito financeiro para os edifícios comerciais, o setor utiliza os fundos de pensão - a maioria deles ligados a empresas estatais, como a Caixa Econômica Federal e a Petrobrás - que funcionaram nos anos de 1980 e 1990 como uma espécie de substituto ao crédito, tentando reproduzir o mecanismo da promoção imobiliária norte-americana. Dessa forma, a financeirização da promoção imobiliária, que nos países centrais se deu ao mesmo tempo que a combinação explosiva das instituições de crédito com o setor imobiliário, adquiriu no Brasil uma outra configuração. $\mathrm{Na}$ ausência do crédito, são os fundos de pensão que, ao assumirem o papel de investidor, aproximam o mercado imobiliário do modo de funcionamento do mercado de capitais. Isso representa uma nova forma de reunir recursos para investimentos, ao considerar a terra um ativo financeiro - porque permite a apropriação de rendas que prometem ser cada vez mais elevadas -, garantindo, assim, rentabilidade. A partir desse enfoque, a autora nos mostra como em São Paulo o capital financeiro transforma a produção imobiliária em títulos mobiliários atraentes para investidores do mercado financeiro. A produção imobiliária nessa parte da cidade passa a ser regida pela busca de liquidez: o imóvel se torna um título mobiliário, e as cidades, sobretudo aquelas com "vocação global" como São Paulo, são financeirizadas.

Para viabilizar essa transformação da paisagem de São Paulo, dotando-a de um status "global", utiliza-se o instrumento da Operação Urbana, aquela mesma forma de parceria público-privada abordada pela autora em seus trabalhos anteriores e responsável por criar as condições necessárias à atração de investidores e à conseqüente submissão da cidade (ou parte dela) à lógica do capital financeiro. Segundo Mariana Fix, a construção da "face global" da cidade de São Paulo, além de ser sustentada por grandes investidores brasileiros, como os fundos de pensão, encontra na parceria entre o poder público e a iniciativa privada o instrumento capaz de viabilizar financeiramente os negócios imobiliários, garantindo fluxo permanente de recursos públicos para modernizar a infra-estrutura na região Faria Lima-Berrini. A Operação Urbana - essa forma de parceria público-privada aplicada no urbano - estimula a produção imobiliária do espaço em áreas inicialmente baratas (próximas às favelas), porém, com localização interessante para a atuação do mercado, que vê na região uma possibilidade de rentabilidade. Assim, o Estado é mobilizado a transformar a cidade em uma "máquina de crescimento" capaz de inseri-la no ranking das cidades com funçóes globais, canalizando recursos públicos que são investidos em infra-estrutura necessária para atrair investimentos imobiliários e 
alavancar negócios privados. Como visto, a Operação Urbana aparece como instrumento que viabiliza o elo financeiro dos empreendimentos imobiliários, mas de forma perversa: concentração de renda e segregação espacial são os resultados da utilização deste instrumento - resultados abordados também em trabalhos anteriores da autora, mas, agora, com destaque para o papel da parceria na relação local-global. Isso contribui para o enfraquecimento do mito criado ao considerar São Paulo uma "cidade global", o que, na verdade, parece ser o caso de apenas uma parte da cidade, direcionada para poucos.

Em segundo lugar, a autora busca nos mostrar como, no caso brasileiro, há uma "fratura" que caracteriza o processo de financeirização e internacionalização da economia, a partir desse estudo sobre São Paulo. Na busca de mobilidade e liquidez, as grandes empresas deixam de se estabelecer em sedes próprias e passam a alugar andares em edifícios construídos naquelas paisagens globalizadas - no exemplo deste livro, a da FariaLima-Berrini -, o que lhes permite se deslocar no território com maior facilidade. Sendo assim, a aparente paisagem globalizada, edificada para servir ao capital transnacional, sofre conseqüências da constante migração que caracteriza as grandes empresas: a alta taxa de vacância dos imóveis e a consequente superoferta dos mesmos acabam provocando a queda dos preços e a fuga de novos investidores. Segundo a autora, o mito das cidades globais já nasce enfraquecido e, por isso, "ganha ares de farsa", apresentando, essas novas centralidades produzidas em São Paulo, o caráter de uma miragem, que busca mimetizar os centros de comando e controle em um país periférico.

Assim, São Paulo, ao reivindicar seu status de "cidade global", tentando ser mais competitiva, reflete sua condição de subordinação e dependência do capitalismo financeirizado. Essa tentativa de readequar a capital paulista às características de uma cidade global revela também as consequiências da implantação da paisagem globalizada - que representa nada mais que a importação de modelos dos pólos de negócios dos países centrais - em uma formação social específica, periférica e "arcaica", destacando, dentre essas conseqüências, o reforço à segregação socioespacial. As estratégias e os instrumentos utilizados para dotar a cidade desse caráter global nos fazem refletir - e, por que não, rever -, no contexto da relação centro-periferia, sobre as re- centes formas de atuação no âmbito do planejamento e da gestão urbana no Brasil. A discussão em torno do instrumento da Operação Urbana e da ação do Estado nas políticas integram essa reflexão. Como abordado na obra de Fix, a construção dessa face empresarial e mundial da cidade de São Paulo se ergueu às custas da segregação socioespacial financiada pelo Estado e pelos fundos de pensão. Ao que parece, a utilização da parceria público-privada como instrumento de planejamento urbano, ao ser aplicado na realidade brasileira, vem servindo aos interesses da acumulação - seja pela sua atuação na produção das condiçóes gerais de produção, na forma de ambiente construído, gerando mais-valias fundiárias, seja viabilizando intervenções associadas a maior permissividade quanto à aplicação de parâmetros urbanísticos, ou financeirizando a produção imobiliária -, em detrimento do caráter redistributivo que caracteriza o discurso da política urbana brasileira mais recente, incluindo-se aí as Operações Urbanas. Cabe refletirmos, a partir do excelente trabalho de Mariana Fix, sobre até que ponto a roupagem de um planejamento democrático e participativo, na forma em que vem se estruturando no Brasil, não estaria, na prática, mascarando estratégias de produção de "cidades empresas".

\section{REFERÊNCIAS}

FIX, Mariana. (2001). Parceiros da exclusão: duas histórias da construção de uma "nova cidade" em São Paulo: Faria Lima e Água Espraiada. São Paulo: Boitempo.

(2003). A fórmula mágica da parceria: Operaçōes Urbanas em São Paulo. In: SCHICCHI, Maria Cristina; BENTAFFI, Dênio. Urbanismo: dossiê São Paulo - Rio de Janeiro (Óculum - Edição Especial). Campinas/Rio de Janeiro: PUCCamp/ PROURB, 2003. (2007). São Paulo, cidade global: fundamentos financeiros de uma miragem. São Paulo: Boitempo. 192 p.

HARVEY, D. (1996). Do gerenciamento ao empresariamento: a transformação urbana no capitalismo tardio. Espaço e Debates, n.39, ano XVI. São Paulo: NERU, p. 48-64. . (1995). Espaços urbanos na "aldeia global": reflexões sobre a condição urbana no capitalismo do final do século 20. (Transcrição de uma conferência proferida em Belo Horizonte, em 1995). 